\title{
Perceived stressors of climate vulnerability across scales in the Savannah zone of Ghana: a participatory approach
}

\author{
Philip Antwi-Agyei ${ }^{1}$ - Claire Helen Quinn ${ }^{2}$ - Samuel Godfried Kwasi Adiku ${ }^{3}$. \\ Samuel Nii Ardey Codjoe ${ }^{4}$ Andrew John Dougill ${ }^{2} \cdot$ Richard Lamboll $^{5}$. \\ Delali Benjamin Komla Dovie ${ }^{4,6}$
}

Received: 18 November 2015/Accepted: 29 March 2016/Published online: 16 June 2016

(C) The Author(s) 2016. This article is published with open access at Springerlink.com

\begin{abstract}
Smallholder farmers in sub-Saharan Africa are confronted with climatic and non-climatic stressors. Research attention has focused on climatic stressors, such as rainfall variability, with few empirical studies exploring non-climatic stressors and how these interact with climatic stressors at multiple scales to affect food security and livelihoods. This focus on climatic factors restricts understanding of the combinations of stressors that exacerbate the vulnerability of farming households and hampers the development of holistic climate change adaptation policies. This study addresses this particular research gap by adopting a multi-scale approach to understand how climatic and non-
\end{abstract}

Editor: Helmut Haberl.

Electronic supplementary material The online version of this article (doi:10.1007/s10113-016-0993-4) contains supplementary material, which is available to authorized users.

Philip Antwi-Agyei

philiantwi@yahoo.com

1 Department of Environmental Science, College of Science, Kwame Nkrumah University of Science and Technology, Kumasi, Ghana

2 Sustainability Research Institute, School of Earth and Environment, University of Leeds, Leeds LS2 9JT, United Kingdom

3 Department of Soil Science, School of Agriculture, University of Ghana, Legon, Ghana

4 Regional Institute for Population Studies, University of Ghana, Legon, Ghana

5 Natural Resources Institute, University of Greenwich, Central Avenue, Chatham Maritime, Kent ME4 4TB, United Kingdom

6 Department of Geography and Resource Development, University of Ghana, Legon, Ghana climatic stressors vary, and interact, across three spatial scales (household, community and district levels) to influence livelihood vulnerability of smallholder farming households in the Savannah zone of northern Ghana. This study across three case study villages utilises a series of participatory tools including semi-structured interviews, key informant interviews and focus group discussions. The incidence, importance, severity and overall risk indices for stressors are calculated at the household, community, and district levels. Results show that climatic and non-climatic stressors were perceived differently; yet, there were a number of common stressors including lack of money, high cost of farm inputs, erratic rainfall, cattle destruction of crops, limited access to markets and lack of agricultural equipment that crossed all scales. Results indicate that the gender of respondents influenced the perception and severity assessment of stressors on rural livelihoods at the community level. Findings suggest a mismatch between local and district level priorities that have implications for policy and development of agricultural and related livelihoods in rural communities. Ghana's climate change adaptation policies need to take a more holistic approach that integrates both climatic and nonclimatic factors to ensure policy coherence between national climate adaptation plans and District development plans.

Keywords Livelihoods - Climate variability - Adaptation . Multi-scale $\cdot$ Food security $\cdot$ Sub-Saharan Africa

\section{Introduction}

Climate change and variability pose considerable threats to agriculture in dryland farming systems that are characterised as vulnerable and with low adaptive capacities (Reynolds et al. 2007). These threats could have 
devastating consequences for farming households in subSaharan Africa, where the majority of the population rely on rain-fed agricultural systems. While farming households in sub-Saharan Africa are accustomed to responding to changes and uncertainties, there is concern that many across the region are reaching the limits of their capacity to cope with further sudden change and uncertainty (Ford et al. 2014; IPCC 2014).

Smallholder farmers in sub-Saharan Africa are confronted with both climatic and non-climatic stressors. Several authors have highlighted the need to understand how climatic variables interact with non-climatic variables (e.g. socio-political and economic factors) to compound the vulnerabilities of households in sub-Saharan Africa (IPCC 2014; Nyantakyi-Frimpong and Bezner-Kerr 2015; Quinn et al. 2011). However, recent research attention has focused mainly on climatic stressors with only more recently emerging empirical studies exploring non-climatic stressors (such as lack of credit facilities or inadequate agricultural equipment) and how these interact with climatic stressors across scales (see Bennett et al. 2015; Tschakert 2007; McCubbin et al. 2015). Focusing on climatic factors only can restrict understanding of the combinations of stressors that exacerbate the vulnerability of farming households to climate change and variability. This gap hampers the development of appropriate policies aimed at integrating non-climatic stressors into the design of climate change adaptation policies in dryland farming systems.

Despite the acknowledgement of the rich knowledge of local people in dealing with change and uncertainties, vulnerability studies have often not incorporated such knowledge in their assessments. As pointed out by Tschakert (2007), the inherent adaptive capacity of smallholder farmers, who are mostly the target population in vulnerability studies, is not considered. Nevertheless, there is an emerging literature in climate change research where local people in dryland farming systems have participated in identifying what predisposes them to climate vulnerability and what undermines their resilience or ability to cope with risk and uncertainty (e.g. Tschakert 2007; Nyantakyi-Frimpong and Bezner-Kerr 2015; McCubbin et al. 2015; Quinn et al. 2011). Tschakert (2007) employed participatory methods to understand key climate and other stressors in the Sahel, while Quinn et al. (2003) studied these issues in rural Tanzania. In putting the views of the vulnerable at the centre of her analysis, Tschakert (2007) concluded that the adaptive capacity of smallholder farmers in central Senegal was greatly influenced by poor health and rural unemployment as well as inadequate village infrastructure. Recently, Nyantakyi-Frimpong and BeznerKerr (2015) adopted a feminist political ecology framework in an ethnographic research to investigate the relative importance of climate change in the context of other risks in two agrarian villages in semi-arid Ghana. This study revealed that "many farmers do not worry about climate change, even in situations where local perceptions and the climate data show a clear pattern of variability" (Nyantakyi-Frimpong and Bezner-Kerr 2015, p. 40).

It needs to be stressed that these previous studies (e.g. McCubbin et al. 2015; Nyantakyi-Frimpong and BeznerKerr 2015; Quinn et al. 2003; Codjoe et al. 2014) have sought to explore vulnerability at a single scale (either at the household, community or national scale). Moreover, many participatory studies focused on factors driving resilience or vulnerability at the local level have overlooked the potential interactions between climatic and nonclimatic factors and how these could exacerbate livelihood vulnerability in dryland farming systems. This paper seeks to address this research gap by identifying climatic and non-climatic stressors and how these stressors interact at three different spatial scales (household, community and district levels) in case study villages in the Central Gonja district of northern Ghana.

This study seeks to answer the following research questions: (1) What existing climatic and non-climatic factors contribute to vulnerability of farming households in the interior savannah zone of northern Ghana? (2) How does the perception of climatic and non-climatic stressors vary across different spatial scales (i.e. households, community and district)? (3) In what ways do climatic and nonclimatic stressors interact at different scales to exacerbate vulnerabilities of rural livelihoods to climate change and variability? These research questions were explored using a participatory approach in a multi-scalar fashion across three farming communities. We argue that broadening our understanding of what constitutes a stress on rural livelihoods and farmers adaptive capacities is critical in designing and prioritising effective adaptation policies, and determining how development interventions can be targeted.

\section{Theoretical framing of vulnerability and multiple stressors to climate change}

The Intergovernmental Panel on Climate Change (IPCC) defines vulnerability (to climate change) as "the degree to which an environmental or social system is susceptible to, and unable to cope with, adverse effects of climate change, including climate variability and extremes" (IPCC 2007, p. 883). As a concept, vulnerability emerged within development debates in the 1990s (Chambers 1994) and has gained traction in climate change research (Fraser et al. 2013; McCubbin et al. 2015).

Vulnerability is conceptualised as a function of the sensitivity, exposure and adaptive capacity of a particular 


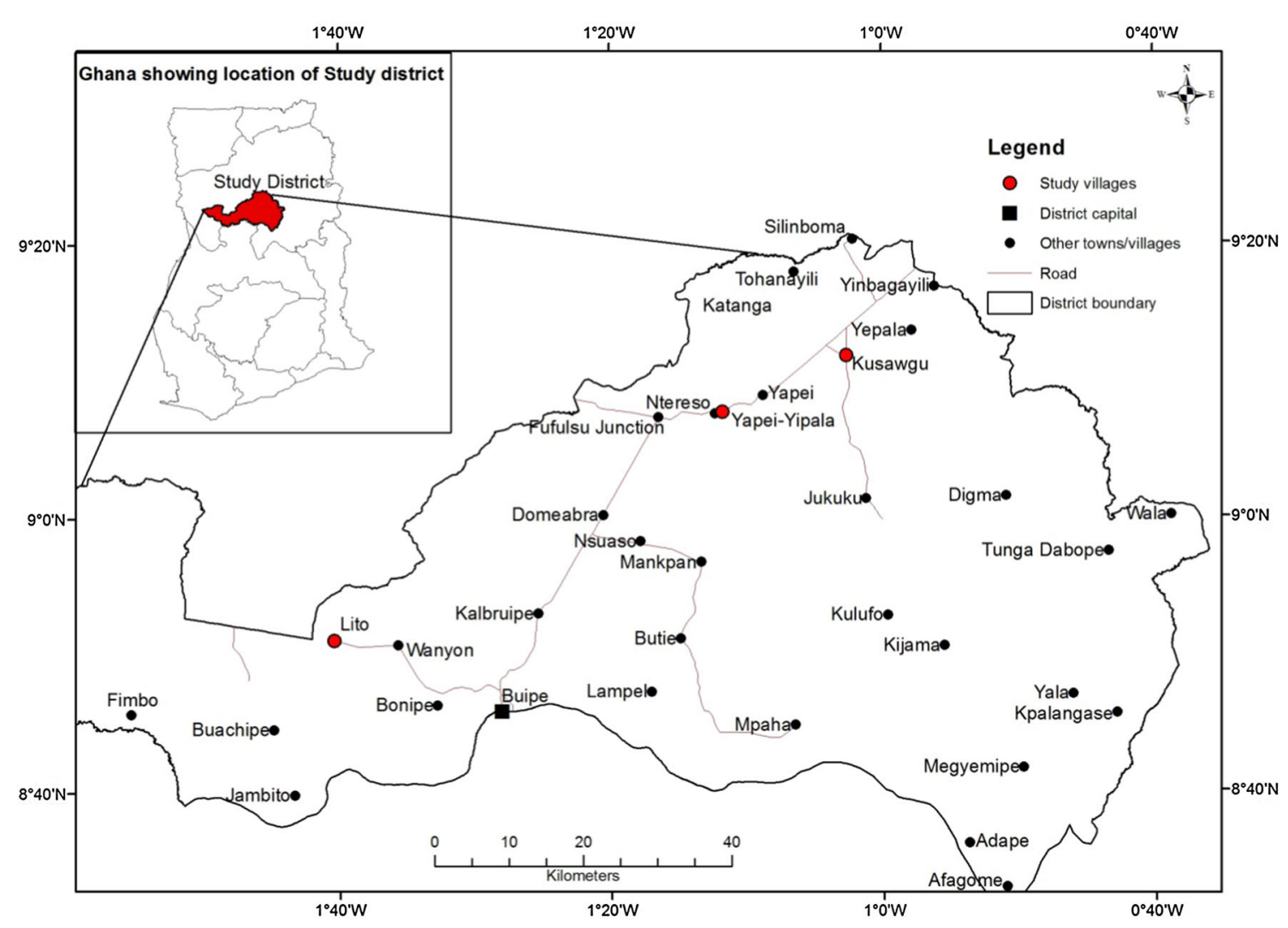

Fig. 1 Central Gonja showing study villages

system. Within the context of climate change and variability, sensitivity is defined as the extent to which a particular system is exposed to climatic stimuli, while exposure refers to the attributes of a system that influence its responses to climate stimuli (Füssel and Klein 2006). Adaptive capacity refers to the ability of a particular system to moderate the adverse impacts of climate change and take advantage of opportunities (Füssel and Klein 2006). In other words, it is the ability to live with stressors. This study operationalised these components of vulnerability by exploring the key stressors that increase vulnerability, thereby hindering smallholder livelihood choices. It is important to understand how multiple stressors can undermine the adaptive capacity of rural households to cope with the adverse impacts of climate change and variability. Vulnerability is context-specific and shaped by various changes in social as well as ecological systems of a particular place (Eakin and Luers 2006; Gunderson and Holling 2002).

The climate change literature is replete with different approaches and methods for assessing the vulnerability of food systems and related livelihoods to climate change. One common approach is to use indicators to derive vulnerability maps for different countries or regions of a country (Atela et al. 2014; Antwi-Agyei et al. 2012). Other researchers have explored vulnerability using a political ecology approach (e.g. NyantakyiFrimpong and Bezner-Kerr 2015; Vásquez-León et al. 2003), whereby social forms including human organisations and how these interact with the environment are analysed (Forsyth 2008). Vásquez-León et al. (2003) demonstrated that within the political context and level, socioeconomic factors such as ethnicity and class, as well as historical inequalities in access to capital resources and technology, are key determining factors influencing the vulnerability of farming households. As these mapping approaches are generally at district or even national scale, vital details about variation at the local scale are often missed. Lack of consideration of local-level experiences of vulnerability can lead to the non-appreciation of indigenous knowledge possessed by local farmers that could have the potential to be harnessed in order to better respond to climate and nonclimatic stressors. It could be argued, therefore, that local-level studies are vital to enhancing the value of vulnerability assessments. 
Table 1 Demographic characteristics of study communities in Central Gonja, Ghana

\begin{tabular}{llll}
\hline Study community & Lito & Kusawgu & Yapei-Yipala \\
\hline Elevation & 771.6 & 538.2 & 433.6 \\
GPS coordinates & N08 $51.111^{\prime}$ & $\mathrm{N}^{\circ} 11.805^{\prime}$ & $\mathrm{N}^{\circ} 09^{\circ} 07.726^{\prime}$ \\
& W001 $40.420^{\prime}$ & $\mathrm{W}^{\circ} 01^{\circ} 02.676^{\prime}$ & $\mathrm{W} 001^{\circ} 11.798^{\prime}$ \\
Population (2014) $)^{\mathrm{a}}$ & 2303 & 1948 & 2171 \\
Total households (2014) & 339 & 213 & 254 \\
No. of study households & 68 & 75 & 76 \\
\% of households studied & 20 & 35 & 30 \\
Average landholding in hectares & 1.95 & 2.46 & 2.25 \\
Nearest market & Buipe market & Yapei market & Yapei market \\
Distance from district capital (km) & 26 & 69 & 51 \\
Ethnicity & Mainly Gonjas & Dagombas and Gonjas & Dagombas and Gonjas \\
Key livelihood activities & Crop production & Crop production & Crop production \\
Focus group discussion (males) & $N=10$ & $N=14$ & $N=16$ \\
Focus group discussion (females) & $N=9$ & $N=12$ & $N=18$ \\
Key informant interviews & $N=4$ & $N=3$ & $N=3$ \\
\hline
\end{tabular}

${ }^{a}$ Population figures are estimates based on the 2010 census data

\section{Research design and study sites}

We conducted our research in the three farming communities of Lito, Kusawgu and Yapei-Yipala, all located in the Central Gonja District of the Northern region of Ghana (Fig. 1; Table 1). Northern region was selected based on a quantitative national vulnerability assessment that identified this region as one of the most vulnerable regions to climate change and variability (Antwi-Agyei et al. 2012). These communities were selected for local-level research, based on information gained through interviews with District level experts at the Ghana's Ministry of Food and Agriculture. These communities are located in the interior savannah ecological zone of Ghana and experience uni-modal rainfall patterns with the rainfall season from May/June to August/ September (Nkrumah et al. 2014). The region's proximity to the Sahel and the Sahara makes it much drier than southern areas of Ghana. Smallholders in these communities are subsistence farmers who produce food crops such as maize, yams, groundnuts and cowpeas. Rearing of cattle, sheep and goats is also common. Agriculture is predominantly rain-fed with farmers depending mainly on natural soil fertility with limited external inputs (MoFA 2007). Loss of vegetative cover due to anthropogenic activities including indiscriminate felling of trees for charcoal and firewood as well as annual bush burning has led to losses in soil fertility. Soil degradation with its catastrophic consequences for local livelihoods is also a major problem in this region (MoFA 2007).

Since the 1960s, northern Ghana has experienced considerable variations in rainfall and temperature compared to the rest of the country (EPA 2007). It is expected that the region will face considerable variation and change in rainfall and temperature in the future. For example, the World Bank reported that temperatures in the three regions of the North will rise by $2.1-2.4^{\circ} \mathrm{C}$ by 2050 compared to the predicted rise of $1.7-2.0^{\circ} \mathrm{C}$ for many other parts of the country including, Eastern, Central, and Volta regions (World Bank 2010). In terms of rainfall, based on the IPCC model ensemble, a reduction of $80 \mathrm{~mm}$ in monthly rainfall during the June-August farming season has been projected for northern Ghana (Christensen et al. 2007). While many parts of southern Ghana experience first rains in March/April, climate models for the northern region suggest a shifting pattern in the onset of the rainy season and indicate that the start of the rains could be in June or even later in July in decades to come (Jung and Kunstmann 2007). This creates uncertainty for farmers in this region concerning when to start the sowing process. The northern region has experienced considerable increase in extreme events such as droughts, bush fires and floods in recent years, and these events have been projected to increase (EPA 2007; Van de Giesen et al. 2010). In addition, the northern regions of Ghana are the poorest regions nationally with high poverty rates and low literacy rates (GSS 2011). Northern Ghana is characterised by poor healthcare facilities and transport infrastructure as well as low rates of access to water and electricity (Pickbourn 2011). The region suffers from recurrent drought as well as economic stagnation and rural out-migration. 


\section{Research methods}

Mixed methods using a variety of participatory tools including semi-structured interviews, key informant interviews, expert interviews and focus group discussions were used to collect data from April to May 2015. The study employed this approach in order to capture the complexity of both climatic and non-climatic stressors, and how rural livelihoods are affected.

Semi-structured interviews were conducted with households, community members and district level personnel at the Ghana's Ministry of Food and Agriculture (MoFA) to identify key stressors on livelihoods (see Table 1). This technique is a standard ethnographic method that allows researchers to gain information on various aspects without preconditioning responses (Bernard 2000). Interviews were conducted directly with respondents in their homes by the lead author, together with 3 trained local field staff. Households were selected in order to ensure a representative sample based on socioeconomic characteristics such as gender and age. This was done through purposive sampling based on local knowledge and key informant information.

The study employed participatory ranking and scoring that enabled smallholder farmers to identify and assess their vulnerability to climate change and variability following Smith et al. (2000) and Tschakert (2007). This approach to data collection and ranking, known as participatory risk mapping, has been found to be both intuitive and practical (Smith et al. 2000). Participatory risk mapping and assessment is gaining traction in development and climate change research (Van Aalst et al. 2008; Webber and Hill 2014). For instance, participatory risk mapping has been used by Webber and Hill (2014) to understand people's perception of crop losses to animals in Uganda. Participatory risk mapping was employed by Fuller et al. (2014) to determine key environmental and population risk factors for malaria vector exposure in northern South America. Hilburn (2015) also used a similar approach to explore garbage-related issues in a rural Mexican municipality. Participatory risk mapping and assessment is simple, cost-effective and enables standardised scores to be compared across scales. This approach also allows for easy communication of results to stakeholders and policy makers (Webber and Hill 2014).

At the household level, a total of 219 semi-structured interviews were conducted in the three communities (Table 1). Questions gathered information about respondents' socioeconomic backgrounds (such as age, gender, and ethnicity), household-level characteristics (including household size, livelihood assets and livelihood strategies) as well as perceptions of various changes within the community. Participants were asked to list the various stressors (i.e. worries, risks, problems, challenges) that they thought increased their livelihood vulnerability or constrained their adaptive capacity, following the approach described by Smith et al. (2000) and Tschakert (2007). Thereafter, they ranked these listed stressors in order of importance, starting with the most important. Participants were given 10 sticks representing a scale of 1 (least severe) to 10 (most severe) to assign to each stated stressor, depending on their perceived severity. Sticks were used because it was easier for study respondents to relate to the sticks and count them. Each interview took between 35 and $60 \mathrm{~min}$ to complete. It is important to stress that respondents were not prompted to consider climate change, neither was the research framed as climate change research.

At the community level, two participatory methods were employed. First, six focus group discussions (FGDs) (two in each community) were conducted with between 9 and 18 participants drawn from different socioeconomic backgrounds according to age, gender and social standing. FGD participants were selected purposefully and included opinion leaders such as chiefs, youth leaders, women's group leaders as well as some selected participants that took part in the household semi-structured interviews. The purpose of these FGDs was to identify stressors at the community level that affected both livelihoods as well as livelihood capital assets and evaluated the main issues highlighted during the household semi-structured interviews. To improve participation of women, separate FGDs were held with female farmers and women's groups. The ranking and severity assessment procedure described above for households was also applied during the FGDs. Second, key informant interviews were conducted with opinion leaders and stakeholders including chiefs, assembly members, chief farmers, and women's group leaders. The purpose of the key informant interviews was to explore the interactions of the various stressors at the community level.

At the district level, a FGD was held with 8 district agricultural development officers in order to identify stressors. Participants were asked to list the various stressors that increased livelihood vulnerability or constrained adaptive capacity of farmers in the district. Sticks were used to quantify severity in similar approach to the household and community levels. Interactions amongst the various stressors were also explored. In addition, expert interviews were held with the district Director of Agriculture and the Deputy District Planning Officer at the Central Gonja district assembly.

Data were entered into Statistical Package for Social Sciences (SPSS). Risk analysis followed an approach similar to that adopted by Tschakert (2007), Quinn et al. (2003) and Smith et al. (2000). For each stressor, an 
incidence index, which represents a measure of the proportion of participants identifying a particular stressor, was calculated. The scale of the incidence index, $I j$, ranged from 0 to 1 . The importance index, $P j,(0-1$ scale) was calculated based on the ranking of the stressor and the number of stressors identified by the same participant as: $P j=-1 \times[(r-1) /(n-1)]+1$, where $r$ is the rank and $n$ is the total number of stressors identified by that respondent (see Tschakert 2007; Bunting et al. 2013). Following this, a risk index, $R$, which incorporates $I j$ and $P j$, was calculated for each stressor as: $R=I j /(2-P j)$ (see Tschakert 2007; Bunting et al. 2013). A severity index, $\mathrm{Si}$, ranging from 1 (least severe) to 10 (most severe) was calculated by the number of sticks interview respondents and focus group participants assigned to a particular stressor (see Tschakert 2007). While the risk index highlighted the most acute risk, the severity index represented the impact of each stressor on human well-being and the communities' effective response to each stressor (Tschakert 2007). The qualitative data collected from both the key informant interviews and FGDs were analysed through intensive content analysis to identify emerging themes and dominant narratives (Krippendorff 2004).

\section{Results}

We first provide results on the nature of climatic and nonclimatic stressors (research question 1). Following this, we provide results on how stressors vary across scales (research question 2) and then present results on the interactions amongst climatic and non-climatic stressors across the scales (research question 3).

\section{Climate and non-climate stressors perceived at the household level}

Farming households identified 24 stressors that they perceived were either increasing the vulnerability of their livelihoods or constraining their adaptive capacity (Fig. 2). The results show that $83 \%$ of the stressors identified at the household level were non-climatic in nature. The two most frequently reported stressors were a lack of money, with an overall risk index of 0.62 , and high cost of farm inputs, with a risk index score of 0.50 (Fig. 2). Other stressors of note at the household level include food insecurity ( $R=0.45)$, high cost of healthcare $(R=0.42)$, low rainfall $(R=0.38)$, lack of agricultural equipment $(R=0.37)$ and a lack of infrastructure $(R=0.34)$. While climatic conditions were noted as influential, these obtained low risk indices, with the exception of a lack of rainfall. For instance, climatic variables such as excessive temperatures and incidences of flood and drought all scored $R<0.30$. Figure 3 illustrates that non-climatic stressors such as lack of money, high cost of farm inputs, food insecurity and high cost of healthcare were all mentioned by more than half of the respondents $(I j>0.50)$ and ranked highest in terms of their importance $(P j>0.50)$ in contributing to livelihood vulnerability at the household level. Other stressors such as lack of electricity and lack of drinking
Fig. 2 Risk index for stressors at household level $(N=219)$

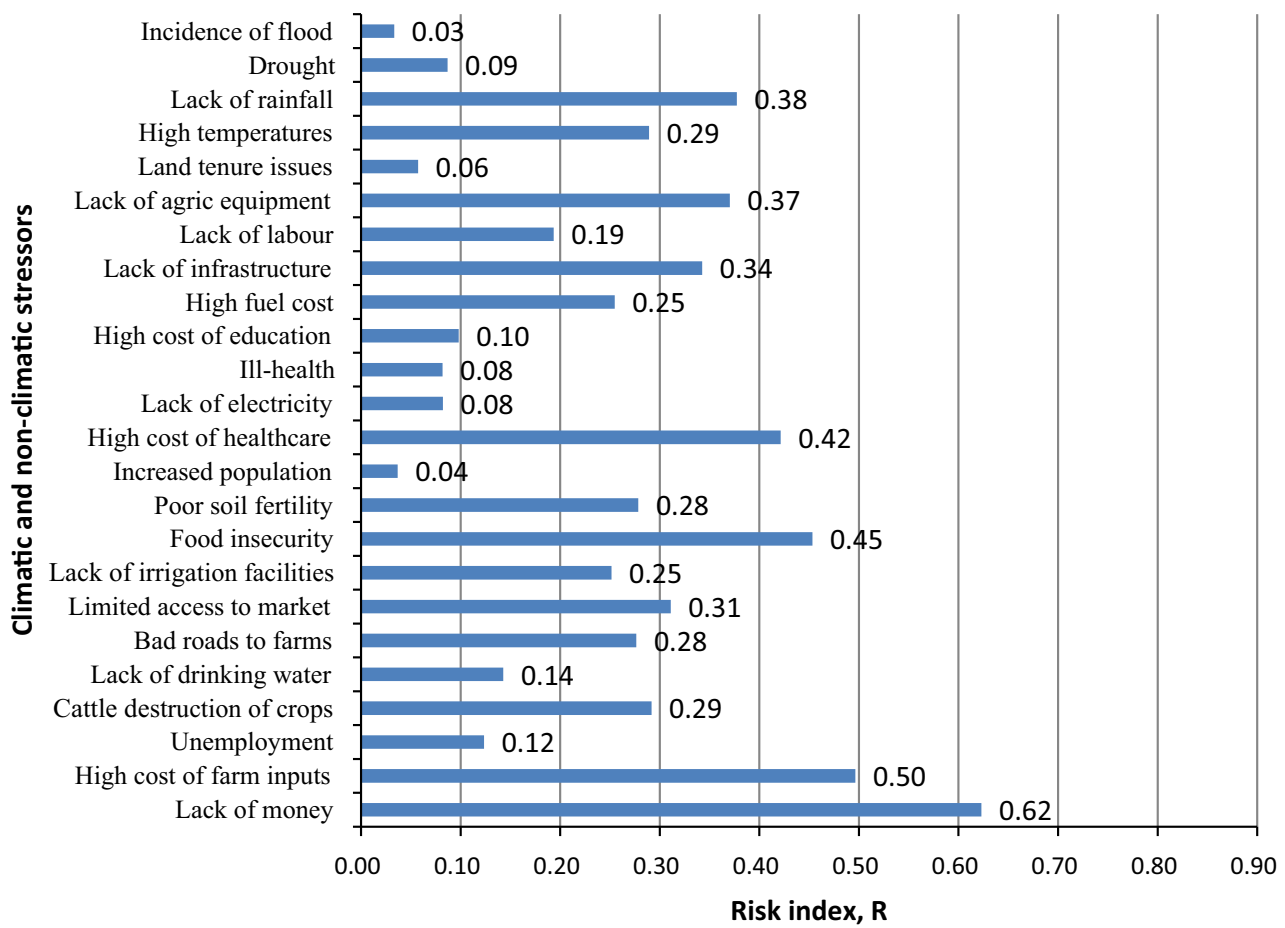




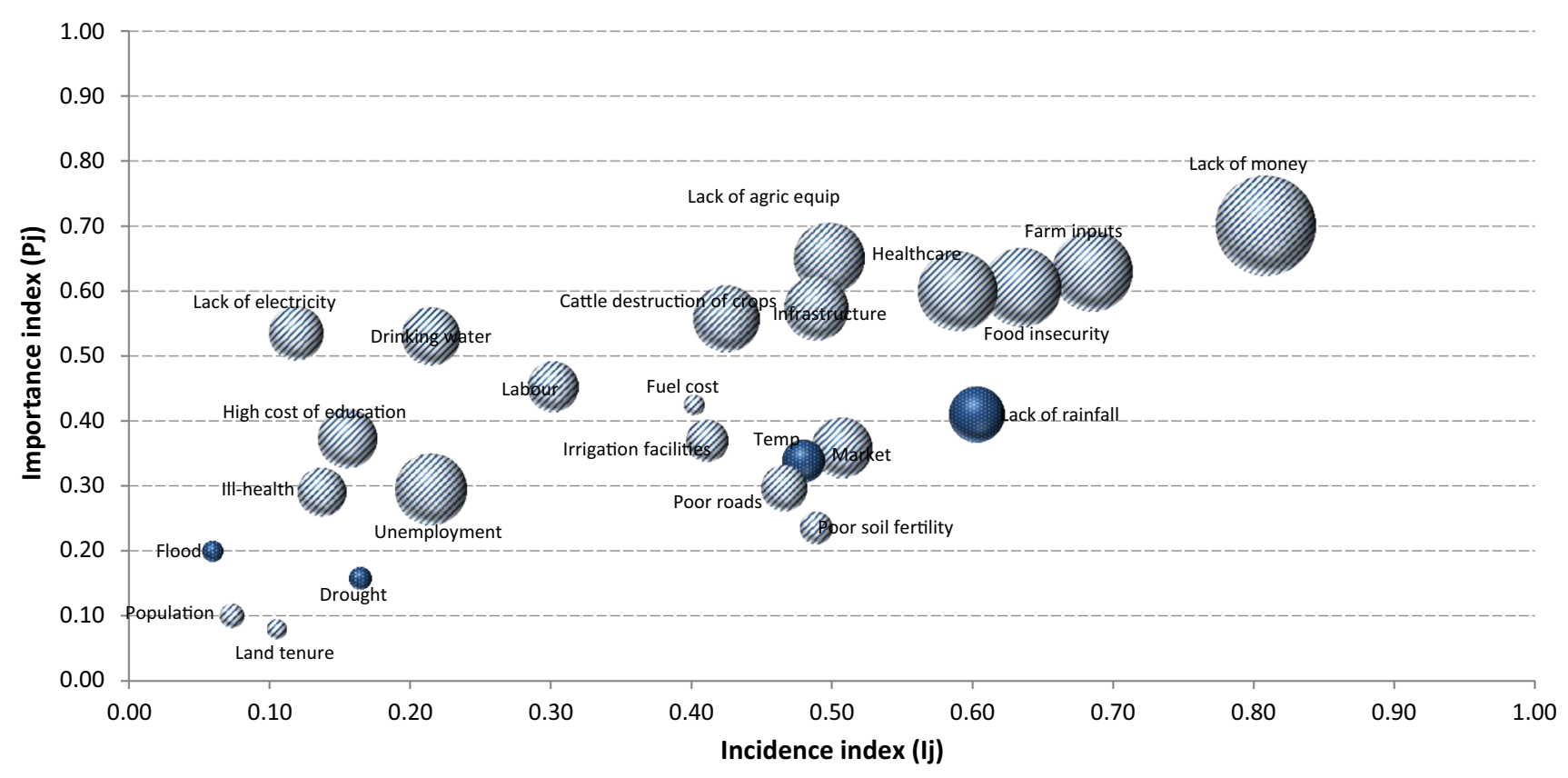

Fig. 3 Participatory ranking of severity of stressors at the household level. NB: the size of each bubble reflects the severity index for that stressor

water were reported by households to have high importance $(P j>0.30)$, but were only mentioned by a small number of households. Other stressors that scored very low incidence indices included increased population and land tenure.

The severity index, expressed through the size of the bubbles in Fig. 3, shows that respondents at the household level considered a lack of money $(S i=7.59)$, high cost of farm inputs $(S i=6.10)$ and high cost of healthcare $(S i=6.04)$ as the most severe stressors at the household level. Other stressors that were ranked as very severe included high food insecurity $(S i=6.00)$, lack of agricultural equipment $(S i=5.38)$, cattle destruction of crops $(S i=5.06)$ and poor village infrastructure $(S i=4.88)$. Lack of money was linked to a lack of employment opportunities and over-dependence on agricultural-based livelihoods. Households reported lower severity for climatic factors such as lack of rainfall $(\mathrm{Si}=4.24)$, high temperatures $(S i=3.25)$, and incidences of flood $(S i=1.61)$. Although low rainfall and drought are related, drought recorded a very low severity index $(S i=1.74)$. This suggests that at the household level, farmers do not consider climate variables as key stressors on their livelihoods.

\section{Variation in perceived stressors across levels}

At the community level, FGD participants identified both climatic and non-climatic stressors that they thought undermined the ability of households to sustain their livelihoods (Table 2). As shown in Fig. 4, socioeconomic stressors such as lack of money, unemployment, lack of agricultural equipment and food insecurity were most often reported ( $\mathrm{i}>0.50 ; \mathrm{Pj}>0.50$ ). The FGDs and key informant interviews identified lack of money $(R=0.88)$ as a key stressor at the community level. Lack of rainfall was the fourth most important stressor at the community level ( $R=0.49$ ) (Table 2$)$. One interesting result at the community level was that climatic stressors recorded slightly higher risk indices. Lack of rainfall had a higher risk index $(R=0.49)$ at community level compared to household level $(R=0.38)$. High temperatures also scored reasonably high at the community level $(R=0.41)$ when compared to household level $(R=0.29)$.

When data are disaggregated according to gender at the community level, the results highlight differences in perceived importance of stressors according to gender (Table 2). Overall, the highest risk indices for female participants in FGDs (following lack of money, which was highest for both male and female groups) were lack of drinking water $(R=0.57)$ and limited access to market $(R=0.52)$. Male respondents in the FGDs recorded $R$ values of 0.20 and 0.27 , respectively, for these stressors. In contrast, men viewed the lack of agricultural equipment as a larger concern $(R=0.77)$ than women $(R=0.34)$. Also, men were more concerned with a lack of irrigation facilities $(R=0.44)$ compared with women $(R=0.22)$. At the community level, the severity index shows that 
Table 2 Overall risk assessment at the community level

\begin{tabular}{|c|c|c|c|}
\hline Stressors & Overall joint risk index & $\begin{array}{l}\text { Risk index } \\
\text { Male FGDs }\end{array}$ & $\begin{array}{l}\text { Risk index } \\
\text { Female FGDs }\end{array}$ \\
\hline Lack of money & 0.88 & 0.89 & 0.86 \\
\hline High cost of farm inputs & 0.33 & 0.33 & 0.34 \\
\hline Lack of agricultural equipment & 0.55 & 0.77 & 0.34 \\
\hline Cattle destruction of crops & 0.38 & 0.33 & 0.42 \\
\hline No electricity & 0.21 & 0.21 & - \\
\hline No drinking water & 0.38 & 0.20 & 0.57 \\
\hline Lack of health facilities & 0.37 & 0.37 & - \\
\hline Unemployment & 0.55 & 0.55 & - \\
\hline Livestock diseases & 0.21 & 0.21 & - \\
\hline Limited access to market & 0.40 & 0.27 & 0.52 \\
\hline Lack of irrigation facilities & 0.33 & 0.44 & 0.22 \\
\hline Lack of veterinary services & 0.12 & 0.12 & - \\
\hline Bush burning & 0.08 & 0.08 & - \\
\hline $\begin{array}{l}\text { Lack of gari processing } \\
\text { machine }\end{array}$ & 0.26 & - & 0.26 \\
\hline Food insecurity & 0.46 & 0.44 & 0.48 \\
\hline Bad roads to farms & 0.10 & 0.10 & - \\
\hline Poor soil fertility & 0.12 & - & 0.12 \\
\hline Lack of improved seeds & 0.22 & 0.17 & 0.26 \\
\hline Increased population & 0.10 & - & 0.10 \\
\hline High cost of healthcare & 0.29 & 0.41 & 0.16 \\
\hline High cost of education & 0.05 & - & 0.05 \\
\hline Lack of storage facilities & 0.18 & 0.10 & 0.26 \\
\hline Lack of rainfall & 0.49 & 0.50 & 0.48 \\
\hline High temperatures & 0.41 & 0.42 & 0.38 \\
\hline
\end{tabular}

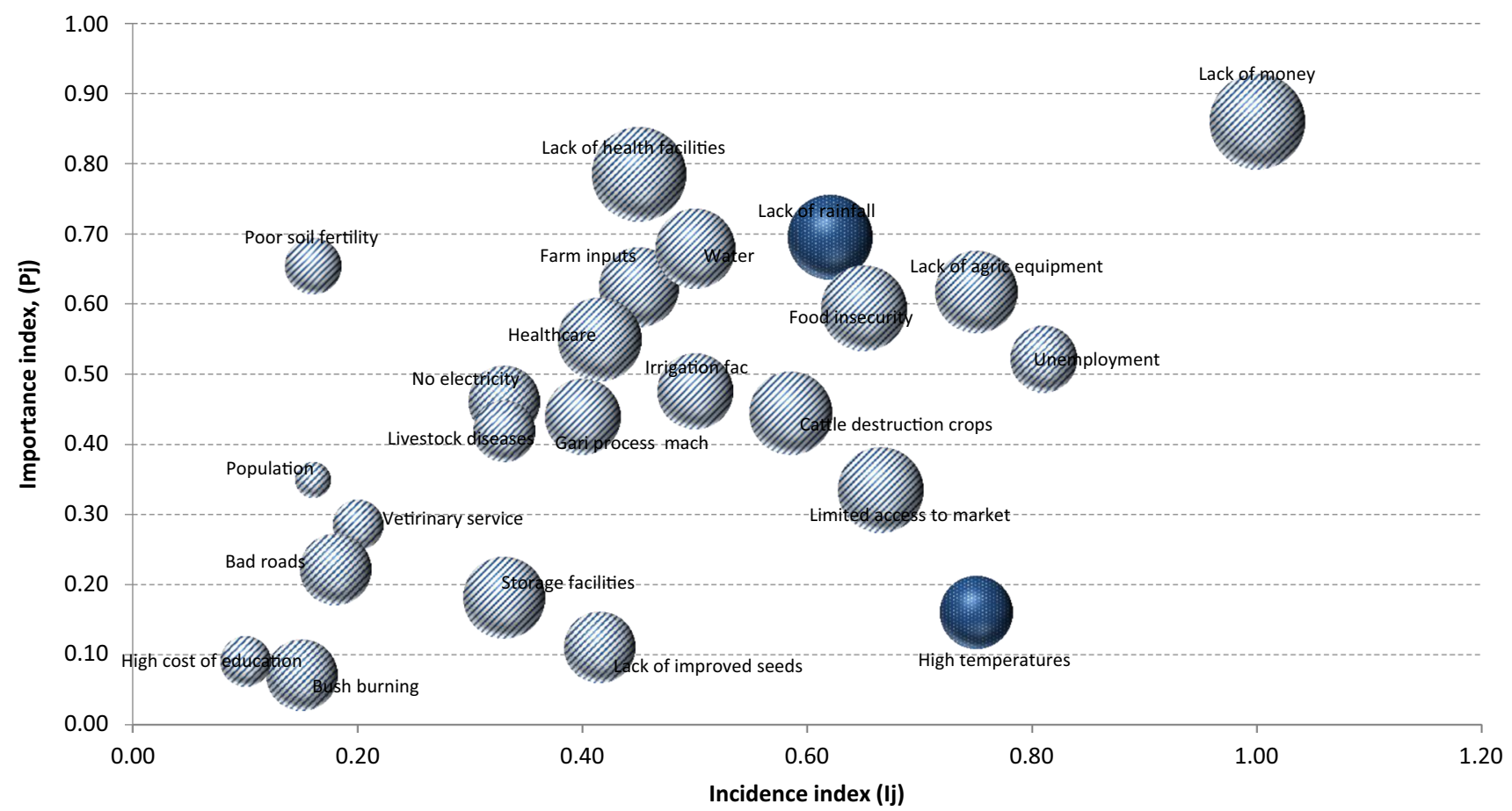

Fig. 4 Participatory assessment of severity of stressors at community level. NB: the size of each bubble reflects the severity index for that stressor 


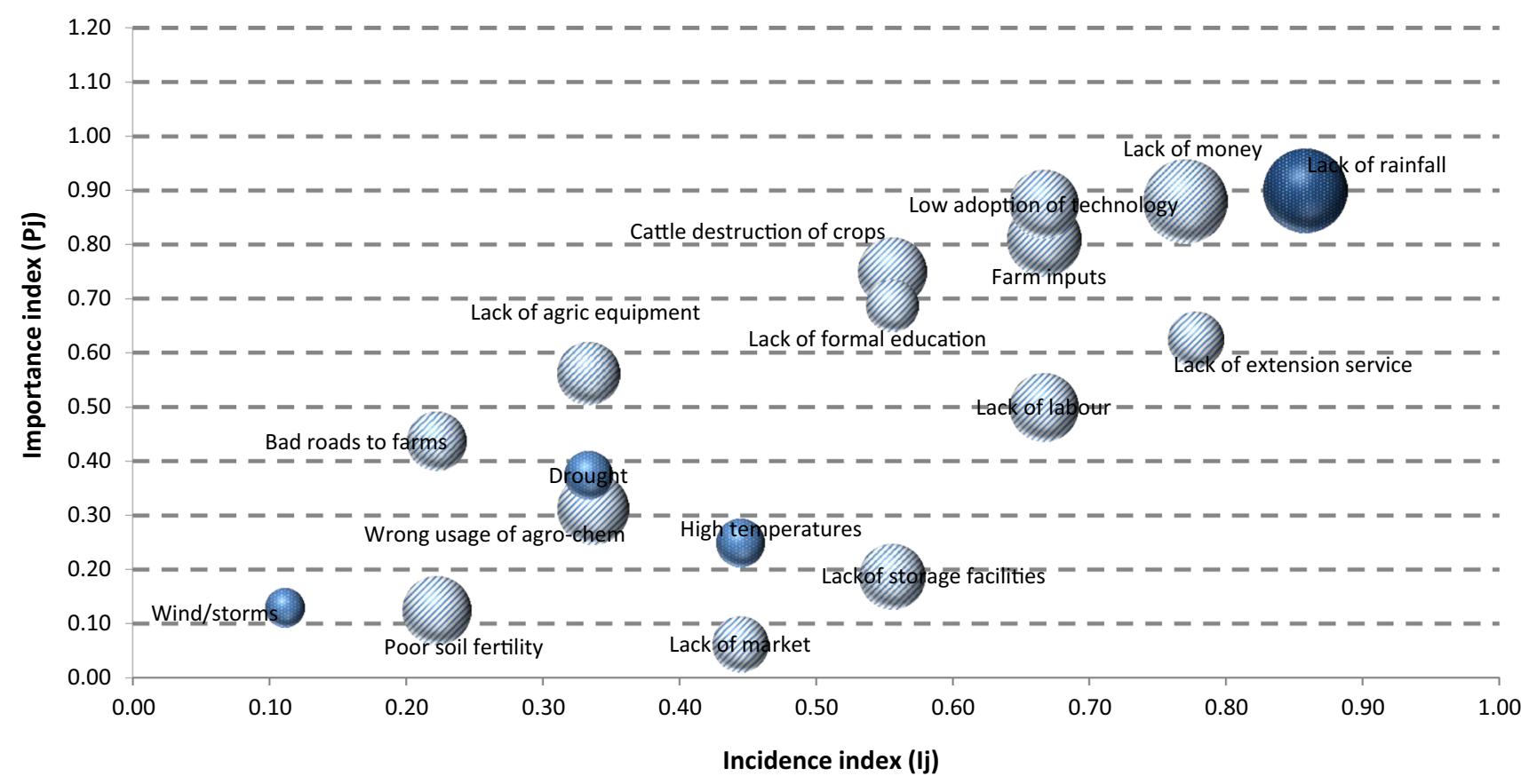

Fig. 5 Participatory assessment of severity of stressors at district level. NB: the size of each bubble reflects the severity index for that stressor

Fig. 6 Risk index at the district level

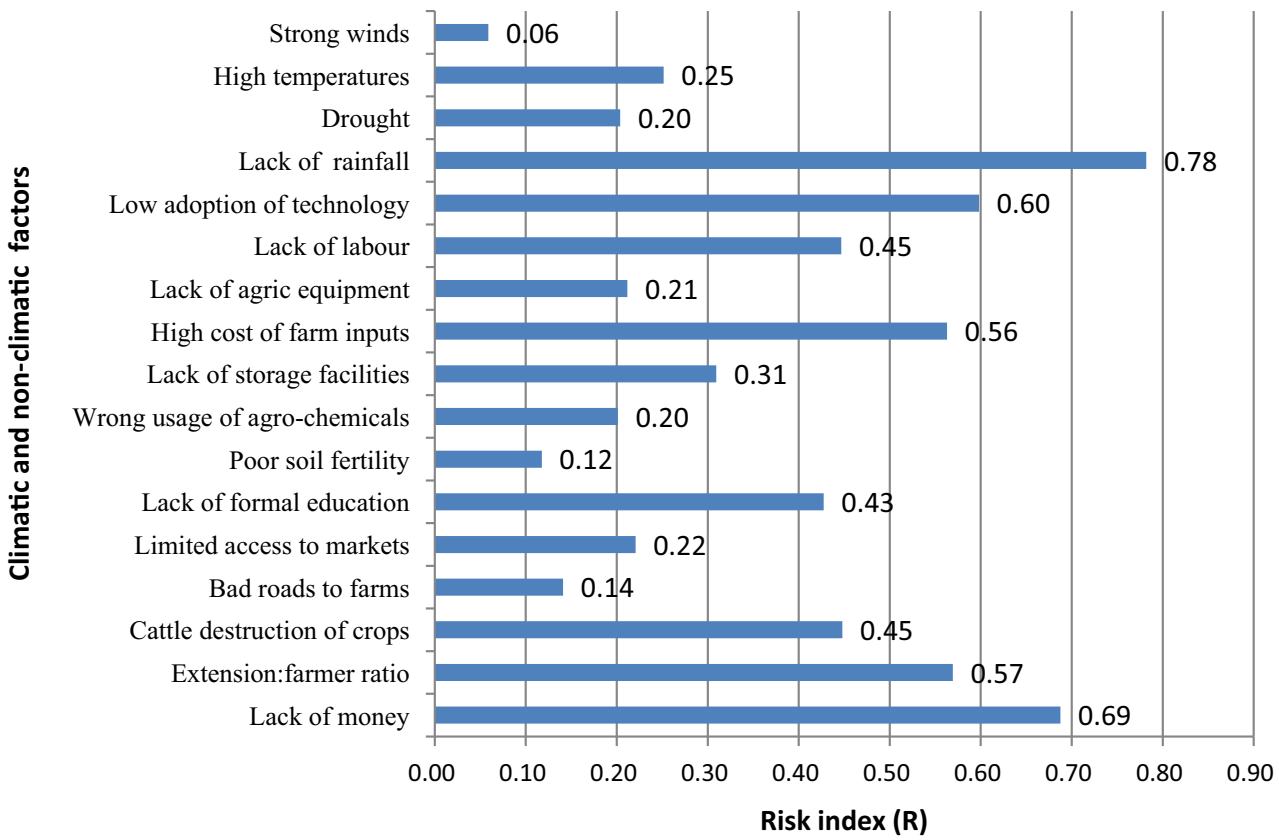

At the district level, FGD participants identified 17 stressors that constrained household adaptive capacity (Fig. 5). Again, many of these stressors were non-climatic comprising a range of socioeconomic, cultural and political factors. However, a lack of rainfall was rated as the most important stressor by respondents at the district level, with risk and severity scores of 0.78 and 9.00 , respectively (Figs. 5, 6). Lack of money was the second most important 


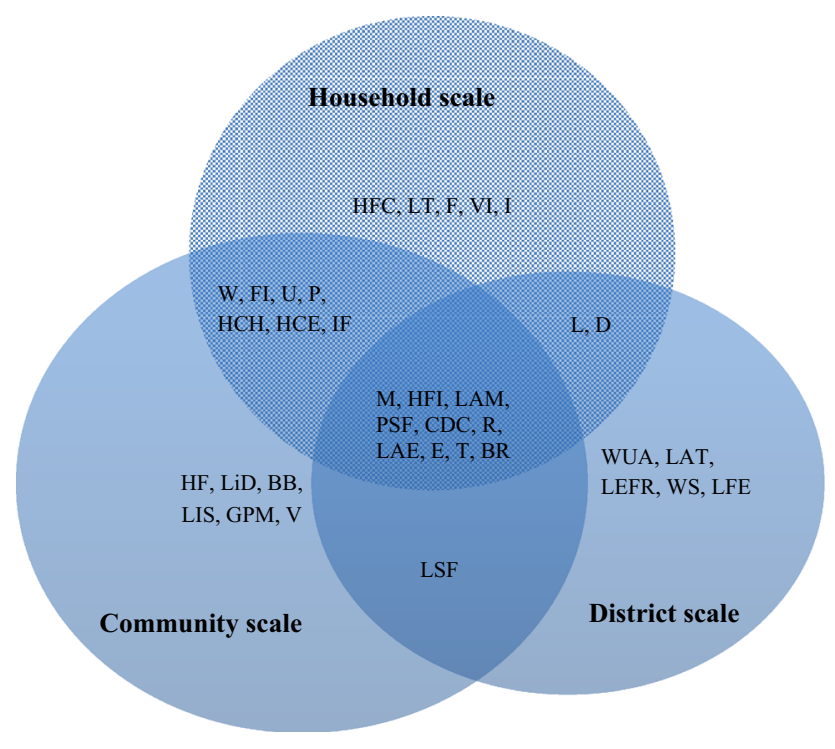

Fig. 7 Perception of stressors across scales. $B B$ bush burning, $B R$ bad roads, $C D C$ cattle destruction of crops, $D$ drought, $E$ electricity, $F$ flood, $F I$ food insecurity, GPM gari processing machine, $H C E$ high cost of education, $H C H$ high cost of healthcare, $H F$ health facilities, $H F C$ high fuel cost, $H F I$ high cost of farm inputs, $I$ ill-health, $I F$ irrigation facilities, $L$ labour, $L A E$ lack of agricultural equipment, $L A M$ limited access to markets, $L A T$ low adoption of technology, $L E F R$ low extension farmer ratio, $L F E$ lack of formal education, $L i D$ livestock diseases, $L I S$ lack of improved seeds, $L S F$ lack of storage facilities, $L T$ land tenure, $M$ lack of money, $P$ population, $P S F$ poor soil fertility, $R$ rainfall, $T$ temperature, $U$ unemployment, $V$ veterinary service, $V I$ village infrastructure, $W$ water, $W S$ wind storms, WUA wrong usage of agrochemicals

stressor, with a risk index of 0.69 and a severity index of 9.00. Stressors including low adoption of technology $(R=0.60 ; S i=6.00)$, low extension to farmer ratio $(R=0.57 ; S i=4.00)$ and cost of farm inputs $(R=0.56$; $S i=7.00)$ were all deemed to considerably impinge on rural livelihoods. Other important stressors identified at the district level were cattle destruction of crops $(R=0.45$; $S i=6.00)$ and lack of labour $(R=0.45 ; S i=6.00)$ (Figs. 5, 6).

A key result emerging from the analysis is the differences in perception regarding the stressors on livelihoods across the various levels (Fig. 7). While the results show that there was consensus at all levels that stressors such as lack of money, limited access to markets, bad roads to farms, cattle destruction of crops and high costs of farm inputs are important, results also point to a discernible mismatch between the perceived stressors at the district level compared to those at the community and household levels. Stressors considered higher risk by both households and communities, such as lack of water and high cost of healthcare, were not considered important at all at the district level, whereas other stressors such as low adoption of technology, inappropriate usage of agro-chemicals and lack of extension services were given higher severity scores at the district level. Further, stressors such as lack of veterinary services, livestock diseases, lack of improved seeds, and a lack of gari (cassava) processing machines were also reported at the community level, although these were never mentioned at the household or district levels.

\section{Interactions amongst climatic and non-climatic stressors}

Through key informant interviews, this study has sought to understand the interactions amongst climatic and non-climatic stressors identified by study communities. Results show that there were interactions amongst the various nonclimatic factors and highlight that non-climatic stressors can compound each other. For instance, a key informant stated: "... the poverty levels in this community are so high and this affects every aspect of our lives. If you do not have money, how do you employ tractor services even when the rains have come? What about farm inputs including improved seeds and getting labour for farm activities? All these require money" [Opinion Leader, Yapei-Yipala, May, 2015]. Another opinion leader noted: “...our roads are in very bad shape and they are almost un-motorable. This makes it difficult for us to convey our foodstuffs from the village to Buipe [the nearest market]. You struggle to get these farm produce and if you cannot get them to the market then it makes life unbearable. The situation is becoming quite depressing..." [Community Leader, Lito, May, 2015]. Another farmer provided further explanation on the interactions between a lack of market and lack of storage facilities during household qualitative interviews: "getting good prices for our produce is also a problem because we cannot store our agricultural produce due to general lack of storage facilities in these communities. In that case, most of us are compelled to sell our produce even at very cheap prices. You cannot bargain much when you have no place to store farm produce" [Female farmer, Lito, April, 2015].

Discussions in FGDs and key informant interviews also revealed that stressors act interdependently to exacerbate the vulnerability of households. For instance, a respondent argued that a lack of money to purchase basic farm inputs and hire tractor services is closely linked to a lack of rainfall in these communities. "Our income is derived mainly from agricultural produce which in turn depends principally on the extent of rainfall in these communities. Hence, the lack of rains especially during the farming season affects crop yield and these affect the amount of money from our produce..." [Key informant interview, Kusawgu, May, 2015]. An Agricultural Development Agent indicated "our roads become un-motorable especially during the rainy season when the roads in these communities become flooded and makes it difficult for 
farmers to convey farm produce to the market. Many drivers do not want to ply these roads during the rainy season. This coupled with lack of storage facility makes farmers vulnerable to market women, who then determine farm prices for farm produce [Agricultural Development Agent, Buipe, May, 2015]. A key informant remarked in an interview: "The lack of good rainfall and environmental condition may play part in the high cost of farm inputs in these communities. This is because you have very few agro-chemical dealers in these communities compared with southern Ghana [where there are lot more dealers and therefore there is competition amongst dealers]..." [Key Informant Interview, May, 2015, Yapei-Yipala]. Another key informant explained that increased levels of household food insecurity in the community were closely linked to insufficient rainfall and drought: "During the lean season, most of the households in this community face difficulties in having food for their families. This is because there are no rains to engage in farming and we do not also have irrigation facilities to enable us farm. Even when you make an attempt to plant, the crops do not do well because of excessive heat, especially during the lean season" [Male farmer, FGD, Lito, April, 2015].

These narratives suggest a strong positive feedback amongst non-climatic and climatic stressors. The livelihood vulnerability of households is often exacerbated by both climatic and non-climatic stressors. One key result emerging from these narratives is that a lack of money underpins many other socioeconomic stressors, including a lack of farm inputs, lack of agricultural equipment and a lack of irrigation facilities. Limited access to market due to bad road networks is linked to excessive rainfall, greatly weakening the bargaining power of the smallholder farmer. Farmers are therefore compelled to accept whatever price is offered for farm produce by middle men. At the same time, a lack of rainfall can lead to low agricultural yields. Therefore, these results indicate that rainfall, whether too much or too little, is a key factor underpinning the lack of money.

\section{Discussion}

The results presented in this paper demonstrate that livelihood vulnerability of smallholder farmers in the interior savannah ecological zone of northern Ghana is affected by many inter-related climatic and non-climatic stressors. Such a finding resonates with other studies that have highlighted that households in dryland farming systems in semi-arid regions respond to a myriad of stressors (Mertz et al. 2010; Nielsen and Reenberg 2010; Tschakert 2007; Quinn et al. 2003, 2011; Reid and Vogel 2006). The results also show that farmers respond to these socioeconomic stressors within the overall context of prevailing climatic variables, including rainfall variability and temperature changes (Leichenko and O'Brien 2008; Reid and Vogel 2006).

Key non-climatic stressors identified at household and community levels include a lack of money, limited access to market, poor village infrastructure, high cost of farm inputs, high cost of healthcare and a lack of storage facilities. Our results also indicate that at the household and community levels, climatic stressors including drought, a lack of rainfall and temperature are not considered as the most critical stressors shaping livelihood vulnerability. Although rainfall variability has been reported to affect food security in northern Ghana (Antwi-Agyei et al. 2012; Wossen and Berger 2015; Armah et al. 2010), the perceived lesser importance attached to climate variables may be due to the fact that most of the study participants have lived in these communities for long periods of time; as such, they have adapted to low rainfall and climate variability.

Lack of money, a non-climatic stressor, was reported as the most important stressor driving livelihood vulnerability in the study communities at both the household and community levels. Lack of money is attributed to lack of both employment and non-farm livelihood opportunities and points to the low profitability of farming, which is at least partially due to limited access to markets (Antwi-Agyei et al. 2013, 2014; Dasgupta and Baschieri 2010). Poverty levels in the northern region and in the study communities in particular are high, with over $70 \%$ of the people in this region living below the poverty line (GSS 2011).

Lack of money is also directly related to the high cost of farm inputs. Most farmers are unable to afford fertilizers as well as high yielding and improved varieties of crops that may hold greater prospects for livelihood security in the face of climate change. High costs of farm inputs and agricultural facilities can be attributed to the structural adjustment programme of the International Monetary Fund embarked upon by the government of Ghana in the 1980s. This programme led to the removal of subsidies for agricultural and farm inputs, including fertilizers, seeds and other agrochemicals (Konadu-Agyemang 2000). Although the high cost of farm inputs was identified as a key stressor, questions remain regarding the availability and use of appropriate external inputs for these semi-arid areas. The results further show that study participants were concerned with poor village infrastructure including healthcare facilities. High cost of healthcare and ill-health, for instance, could undermine the adaptive capacity of households and predispose them to increased climate change vulnerability (Woodward et al. 2014; Campbell-Lendrum et al. 2015).

The results demonstrate that gender of respondents also partly influences perceptions of stressors. For instance, 
while women were more concerned about a lack of drinking water, food insecurity and a lack of storage facilities, men were more concerned about a lack of irrigation facilities or a lack of agricultural equipment. Traditionally, in typical Ghanaian culture, like many other sub-Saharan Africa countries, women are responsible for collecting household drinking water and are also expected to provide food for the family (Pickbourn 2011). These traditional roles are reflected in the stressors identified by women. In many parts across Africa, women can walk an average of 3.7 miles per day to collect water for the household (World Water Assessment Programme 2015). This leaves women limited time to spend on their own farms, with implications for food security. Although land tenure was not cited as a major stressor, recording an overall risk index of 0.06 , the results show that the majority of the $11 \%$ that cited this stressor were female. This may be due to the complex land tenure arrangements in northern Ghana (Yaro 2010), which further undermine the adaptive capacity of female farmers (Antwi-Agyei et al. 2015). In contrast, the stressors identified by male participants (irrigation and agricultural equipment) reflect the roles of men in many dryland agrarian settings in sub-Saharan Africa, where they typically control assets and resources that could enhance household's adaptive capacity (Naab and Koranteng 2012). Such differences in perceptions on stressors therefore correlate with the sexual division of labour commonly found in dryland farming systems. The differences in perception between male and female farmers have implications for climate change adaptation policies. For instance, one-size-fits-all approaches to climate change policy making in dryland farming systems can miss key gender dynamics, making such approaches less effective (Tschakert, 2007). In this sense, gender-sensitive climate change adaptation policies should be vigorously pursued by policy makers.

The results suggest that stakeholders at different levels perceive different stressors. For instance, stressors including livestock disease and a lack of veterinary services were considered critical at the community level, especially by male farmers. Yet, these stressors were not mentioned at all at the household level. The differences in perceived stressors between respondents to the semi-structured interviews at the household level and those in the FGDs at the community level may be explained by fact that at the household level, farmers were more concerned with stressors they could control or stressors that affected them directly such as lack of money, limited access to farm inputs and lack of agricultural facilities. At the community level, the FGD participants highly rated stressors that affected the community as a whole and might be controlled at that level.

The findings also suggest a mismatch between local and district level priorities, which may have implications for adaptation policy processes and development of agricultural and related livelihoods. This is because although agricultural development interventions and decisions are taken at district and national levels, they are often implemented at the local level and will have an influence on households and communities. If perceptions of key stressors on livelihoods vary between district level planners and extension services on the one hand and local farmers on the other, then local level priorities may be overridden by district level perceptions. It is important to note that district level perceptions may also be influenced by national and international strategies and action plans such as National Adaptation Programmes of Action (NAPAs) and other climate focused policies where emphasis is placed on climatic stressors and adaptation to them. It is important that national and district level planning develop policies that encourage action and adaptation responses that enable farmers to cope with and adapt to multiple stressors. In this way, national and district policy could align much better with local priorities and avoid promotion of actions that might enable adaptation to climatic stressors at the cost of increased vulnerability to non-climatic ones. This can be done by providing a common platform for district level extension officers, planners as well as members of the local community to interact and develop a common understanding of what constitutes stress on rural livelihoods. In this regard, appropriate communication tools including the use of local dialects should be advocated.

Our results demonstrate interactions between climatic and non-climatic stressors in the study communities. Limited access to markets is closely linked to the poor road infrastructure and transport network that compounds livelihood challenges. The poor road infrastructure is likely to be increasingly strained by increasing instances of storms and floods under climate change, further exacerbating the poverty situation in these communities because farmers cannot sell their farm produce in good time (Zhang et al. 2007). Similarly, food insecurity as a non-climatic stressor can be linked to floods and droughts in the study communities. For instance, excessive rainfall within a short period, closely linked to climate change, in the study communities sometimes led to flooding of food crops and livestock, resulting in food insecurity.

The implications of multiple interacting climatic and non-climatic stressors needs to be carefully considered. The findings from this study demonstrate the need for policy to go beyond scenario-based climate change impacts on livelihoods to consider the range of socioeconomic and political impacts too. For Ghana, and other countries in sub-Saharan Africa, this means linking climate change adaptation policies to poverty reduction strategies. This could ensure economic development and increased adaptive capacity for poor small-holder farmers, reducing their 
exposure to both climatic and non-climatic stressors. Further, enabling economic conditions should be created so that farmers can access loans and credit facilities for their farming and non-farm livelihood activities. In addition, skill provision for small-holder farmers should be given priority by policy makers as part of the overall climate change adaptation policy. This would enhance the capacity of farmers to engage in non-farm livelihood activities that may be less impacted by climate change. The findings also corroborate other studies that suggest that for rural small-scale farmers who have poor access to resources, vulnerability to climate change and variability are compounded by lack of road infrastructure and access to vibrant markets (Reid and Vogel 2006; Bunting et al. 2013). This situation is likely to worsen, with climate change predicted to disrupt road infrastructure in Africa (Chinowsky et al. 2013).

The interactions between climatic and non-climatic stressors have serious implications for food security and related livelihoods. Food insecurity is a major problem that affects most households in the northern region of Ghana (Armah et al. 2010) as well as elsewhere across sub-Saharan Africa. Most of the households in the study communities engaged in subsistence agriculture to feed their immediate family members, and there were several instances of food insecurity directly linked to rainfall variability. This situation is, perhaps, attributable to the over-dependence of these study communities on rain-fed agricultural systems. Hence, the duration, timing and amount of rainfall directly determines crop productivity.

\section{Conclusions and policy implications}

This study has empirically demonstrated that smallholder farmers in rural semi-arid farming systems are confronted with multiple stressors including both socioeconomic and climatic stressors. The novelty of this paper lies in its exploration of the perceptions of stressors on rural livelihoods across multiple scales. Participants at household, community and district levels identified key stressors that increase livelihood vulnerability. The results show that stakeholders at different levels perceived the climatic and non-climatic stressors faced by farmers differently; however, there were a number of common stressors identified, including lack of money, high cost of farm inputs, erratic rainfall, cattle destruction of crops, poor soil fertility, limited access to markets and lack of agricultural equipment.

Although climatic variables (with the exception of rainfall) were not rated as critical to increasing livelihood vulnerability to climate change at the household and community levels, climatic variables such as rainfall variability and increased temperatures were rated highly at the district level. Results indicate that gender influences the perception and severity assessment of stressors on rural livelihoods at the community level.

The findings from this paper have important implications for policy and practice. Firstly, there is the need to incorporate non-climatic or socioeconomic stressors into climate change adaptation policy formulation in dryland farming systems. Understanding what constitutes a stress on rural livelihoods is critical in designing and prioritising effective adaptation policies. Secondly, the mismatch between district level and local level perceived stressors on rural livelihoods could result in incorrect policy interventions and misapplication of scarce resources.

While not downplaying the significance of managing the adverse impacts of climate change on agrarian livelihoods, this study has highlighted the significance of tackling both climatic and non-climatic stressors. Tackling non-climatic stressors will invariably enhance the capacity of farming households to confront the challenges posed by climatic change on food security and livelihoods.

Acknowledgments This research was supported by funding from the Department for International Development (DfID) under the Climate Impact Research Capacity and Leadership Enhancement (CIRCLE) programme. The authors are grateful to the Regional Institute for Population Studies, University of Ghana, Legon, for hosting the lead author as a Visiting Research Fellow. The authors also acknowledge the support of participating communities in this study.

Open Access This article is distributed under the terms of the Creative Commons Attribution 4.0 International License (http://crea tivecommons.org/licenses/by/4.0/), which permits unrestricted use, distribution, and reproduction in any medium, provided you give appropriate credit to the original author(s) and the source, provide a link to the Creative Commons license, and indicate if changes were made.

\section{References}

Antwi-Agyei P, Fraser EDG, Dougill AJ, Stringer LC, Simelton E (2012) Mapping the vulnerability of crop production to drought in Ghana using rainfall, yield and socioeconomic data. Appl Geogr 32:324-334. doi:10.1016/j.apgeog.2011.06.010

Antwi-Agyei P, Dougill AJ, Fraser EDG, Stringer LC (2013) Characterising the nature of household vulnerability to climate variability: empirical evidence from two regions of Ghana. Environ Dev Sustain 15:903-926. doi:10.1007/s10668-012-9418-9

Antwi-Agyei P, Stringer LC, Dougill AJ (2014) Livelihoods adaptation to climate variability: insights from farming households in Ghana. Reg Environ Change 14:1615-1626. doi:10.1007/ s10113-014-0597-9

Antwi-Agyei P, Dougill AJ, Stringer LC (2015) Impacts of land tenure arrangements on the adaptive capacity of marginalized groups: the case of Ghana's Ejura Sekyedumase and Bongo districts. Land Use Policy 49:203-212. doi:10.1016/j.landusepol. 2015.08.007 
Armah FA, Yawson DO, Yengoh GT, Odoi JO, Afrifa EKA (2010) Impact of floods on livelihoods and vulnerability of natural resource dependent communities in northern Ghana. Water 2:120-139. doi:10.3390/w2020120

Atela JO, Quinn CH, Minang PA (2014) Are REDD projects pro-poor in their spatial targeting? Evidence from Kenya. Appl Geogr 52:14-24. doi:10.1016/j.apgeog.2014.04.009

Bennett NJ, Dearden P, Peredo AM (2015) Vulnerability to multiple stressors in coastal communities: a study of the Andaman Coast of Thailand. Clim Dev 7:124-141. doi:10.1080/17565529.2014. 886993

Bernard HR (2000) Social research methods: qualitative and quantitative approaches. Sage, Beverley Hills

Bunting E, Steele J, Keys E, Muyengwa S, Child B, Southworth J (2013) Local perception of risk to livelihoods in the semi-arid landscape of Southern Africa. Land 2:225-251. doi:10.3390/ land 2020225

Campbell-Lendrum D, Manga L, Bagayoko M, Sommerfeld J (2015) Climate change and vector-borne diseases: what are the implications for public health research and policy? Philos Trans R Soc B. doi:10.1098/rstb.2013.0552

Chambers R (1994) The origins and practice of participatory rural appraisal. World Dev 22:953-969

Chinowsky P, Schweikert A, Strzepek N, Manahan K, Strzepek K, Schlosser CA (2013) Climate change adaptation advantage for African road infrastructure. Clim Change 117:345-361. doi:10. 1007/s10584-012-0536-Z

Christensen JH, Hewitson B, Busuioc A, Chen A, Gao X, Held R, Jones R, Kolli RK, Kwon W, Laprise R (2007) Regional climate projections: climate change: The Physical Science Basis. Contribution of Working Group I to the Fourth Assessment Report of the Intergovernmental Panel on Climate Change. Cambridge University Press, Cambridge

Codjoe SNA, Owusu G, Burkett V (2014) Perception, experience, and indigenous knowledge of climate change and variability: the case of Accra, a sub-Saharan African city. Reg Environ Change 14:369-383. doi:10.1007/s10113-013-0500-0

Dasgupta A, Baschieri A (2010) Vulnerability to climate change in rural Ghana: mainstreaming climate change in poverty reduction strategies. J Int Dev 22:803-820. doi:10.1002/jid.1666

Eakin H, Luers AL (2006) Assessing the vulnerability of socialenvironmental systems. Ann Rev Environ Res 31:365-394. doi:10.1146/annurev.energy.30.050504.144352

EPA (2007) Climate change and the Ghanaian economy. Policy Advice Series Volume 1. Environmental Protection Agency, Accra

Ford JD, Berrang-Ford L, Bunce A, McKay C, Irwin M, Pearce T (2014) The status of climate change adaptation in Africa and Asia. Reg Environ Change 15:801-814. doi:10.1007/s10113014-0648-2

Forsyth T (2008) Political ecology and the epistemology of social justice. Geoforum 39:756-764. doi:10.1016/j.geoforum.2006.12.005

Fraser EDG, Simelton E, Termansen M, Gosling SN, South A (2013) "Vulnerability hotspots": integrating socio-economic and hydrological models to identify where cereal production may decline in the future due to climate change induced drought. Agric For Meteorol 170:195-205. doi:10.1016/j.agrformet.2012.04.008

Fuller DO, Troyo A, Alimi TO, Beier JC (2014) Participatory risk mapping of malaria vector exposure in Northern South America using environmental and population data. Appl Geogr 1(48):1-7. doi:10.1016/j.apgeog.2014.01.002

Füssel HM, Klein RJT (2006) Climate change vulnerability assessments: an evolution of conceptual thinking. Clim Change 75:301-329. doi:10.1007/s10584-006-0329-3

GSS (2011) Population and housing census (2010). Ghana Statistical Service, Accra
Gunderson LH, Holling CS (2002) Panarchy: understanding transformations in human and natural systems. Island Press, Washington, DC

Hilburn AM (2015) Participatory risk mapping of garbage-related issues in a rural Mexican municipality. Geogr Rev 105(1):41-60. doi:10.1111/j.1931-0846.2014.12044.x

IPCC (2007) Climate change 2007: impacts, adaptation and vulnerability. Contribution of Working Group II to the Fourth Assessment Report of the Intergovernmental Panel on Climate Change. Cambridge University Press, Cambridge

IPCC (2014) Climate change 2014: impacts, adaptation and vulnerability: contribution of working group II to the IPCC fifth assessment report. University Press Cambridge, Cambridge

Jung G, Kunstmann H (2007) High-resolution regional climate modelling for the Volta Basin of West Africa. J Geophys Res 112:17. doi: $10.1029 / 2006 J D 007951$

Konadu-Agyemang K (2000) The best of times and the worst of times: structural adjustment programs and uneven development in Africa: the case of Ghana. Prof Geogr 52:469-483. doi:10. 1111/0033-0124.00239

Krippendorff K (2004) Content analysis: an introduction to its methodology. Sage, Thousand Oaks

Leichenko RM, O'Brien KL (2008) Environmental change and globalization: double exposures. Oxford University Press, Oxford

McCubbin S, Smit B, Pearce T (2015) Where does climate fit? Vulnerability to climate change in the context of multiple stressors in Funafuti, Tuvalu. Glob Environ Change 30:43-55. doi:10.1016/j.gloenvcha.2014.10.007

Mertz O, Mbow C, Nielsen JØ, Maiga A, Diallo D, Reenberg A, Diouf A, Barbier B, Moussa IB, Zorom M (2010) Climate factors play a limited role for past adaptation strategies in West Africa. Ecol Soc 15:25

MoFA (2007) Food and agriculture sector development policy. Ministry of Food and Agriculture, Accra

Naab JB, Koranteng H (2012) Gender and Climate Change Research Results: Jirapa, Ghana Working Paper No. 17. CGIAR Research Program on Climate Change, Agriculture and Food Security (CCAFS). Nairobi, Kenya. http://r4d.dfid.gov.uk/PDF/Outputs/ CCAFS/ccafs-wp-17-gender_adaptation_ghana.pdf. Accessed 20 Aug 2014

Nielsen JO, Reenberg A (2010) Cultural barriers to climate change adaptation: a case study from Northern Burkina Faso. Glob Environ Change 20:142-152. doi:10.1016/j.gloenvcha.2009.10. 002

Nkrumah F, Klutse NAB, Adukpo DC, Owusu K, Quagraine KA, Owusu A, Gutowski W Jr (2014) Rainfall variability over Ghana: model versus rain gauge observation. Int $\mathrm{J}$ Geosci 5:673-683. doi:10.4236/ijg.2014.57060

Nyantakyi-Frimpong H, Bezner-Kerr R (2015) The relative importance of climate change in the context of multiple stressors in semi-arid Ghana. Glob Environ Change 32:40-56. doi:10.1016/j. gloenvcha.2015.03.003

Pickbourn LJ (2011) Migration, remittances and intra-household allocation in northern Ghana: does gender matter? Ph.D. Dissertation, University of Massachusetts, Amherst

Quinn CH, Huby M, Kiwasil H, Lovett JC (2003) Local perceptions of risk to livelihood in semi-arid Tanzania. J Environ Manag 68:111-119. doi:10.1016/S0301-4797(03)00013-6

Quinn CH, Ziervogel G, Taylor A, Takama T, Thomalla F (2011) Coping with multiple stresses in rural South Africa. Ecol Soc 16:2. doi:10.5751/ES-04216-160302

Reid P, Vogel C (2006) Living and responding to multiple stressors in South Africa: glimpses from KwaZulu-Natal. Glob Environ Change 16:195-206. doi:10.1016/j.gloenvcha.2006.01.003 
Reynolds JF, Smith D, Lambin EF, Turner B, Mortimore M, Batterbury SPJ, Downing TE, Dowlatabadi H, Fernández RJ, Herrick JE (2007) Global desertification: building a science for dryland development. Science 316:847-851. doi:10.1126/ science. 1131634

Smith K, Barrett CB, Box PW (2000) Participatory risk mapping for targeting research and assistance: with an example from East African pastoralists. World Dev 28:1945-1959. doi:10.1016/ S0305-750X(00)00053-X

Tschakert P (2007) Views from the vulnerable: understanding climatic and other stressors in the Sahel. Glob Environ Change 17:381-396. doi:10.1016/j.gloenvcha.2006.11.008

Van Aalst MK, Cannon T, Burton I (2008) Community level adaptation to climate change: the potential role of participatory community risk assessment. Glob Environ Change 18(1): 165-179. doi:10.1016/j.gloenvcha.2007.06.002

Van de Giesen N, Liebe J, Jung G (2010) Adapting to climate change in the Volta Basin, West Africa. Curr Sci 98(8):1033-1038

Vásquez-León M, West CT, Finan TJ (2003) A comparative assessment of climate vulnerability: agriculture and ranching on both sides of the US-Mexico border. Glob Environ Change 13:159-173. doi:10.1016/S0959-3780(03)00034-7

Webber AD, Hill CM (2014) Using participatory risk mapping (PRM) to identify and understand people's perceptions of crop loss to animals in Uganda. PLoS One 9(7):e102912. doi:10.1371/ journal.pone.0102912

Woodward A, Smith KR, Campbell-Lendrum D, Chadee DD, Honda Y, Liu Q, Olwoch J, Revich B, Sauerborn R, Chafe Z, Confalonieri U, Haines A (2014) Climate change and health: on the latest IPCC report. Lancet 383:1185-1189. doi:10.1016/ S0140-6736(14),60576-6

World Bank (2010) Economics of adaptation to climate change. Ghana Country Study; World Bank, Washington

World Water Assessment Programme (2015) Water for women: every woman counts. Every second counts. UNESCO. http://www. unwater.org/fileadmin/user_upload/worldwaterday2015/docs/ Water\%20For\%20Women.pdf. Accessed 17 Oct 2015

Wossen T, Berger T (2015) Climate variability, food security and poverty: agent-based assessment of policy options for farm households in Northern Ghana. Environ Sci Policy 47:95-107. doi:10.1016/j.envsci.2014.11.009

Yaro JA (2010) Customary tenure systems under siege: contemporary access to land in Northern Ghana. GeoJournal 75:199-214. doi:10.1007/s10708-009-9301-x

Zhang X, Rockmore M, Chamberlin J (2007) A typology for vulnerability and agriculture in sub-Saharan Africa. International Food Policy Research Institute, Washington 